Research Article

\title{
Experimental Research on the Influence of Temperature on the Static Properties of Skarn
}

\author{
Lei Liu $\mathbb{D},{ }^{1,2}$ Xiang Meng $\mathbb{D}^{3}$ Hao Qin $\mathbb{D}^{1},{ }^{1}$ and Zhaozhao Chang $\mathbb{D}^{4}$ \\ ${ }^{1}$ Faculty of Land Resources Engineering, Kunming University of Science and Technology, Kunming 650093, China \\ ${ }^{2}$ Yunnan Key Laboratory of Sino-German Blue Mining and Utilization of Special Underground Space, \\ Kunming University of Science and Technology, Kunming 650093, China \\ ${ }^{3}$ Faculty of Public Security and Emergency Management, Kunming University of Science and Technology, Kunming 650093, \\ China \\ ${ }^{4}$ School of Management, Xi'an University of Architecture and Technology, Xi'an 710055, China
}

Correspondence should be addressed to Zhaozhao Chang; changzz2018@xauat.edu.cn

Received 24 January 2021; Revised 4 March 2021; Accepted 19 March 2021; Published 9 April 2021

Academic Editor: Hualei Zhang

Copyright (C) 2021 Lei Liu et al. This is an open access article distributed under the Creative Commons Attribution License, which permits unrestricted use, distribution, and reproduction in any medium, provided the original work is properly cited.

Studying the high-temperature mechanical properties of rocks is of great significance to engineering disasters caused by deep rock mining and underground protection projects. In view of insufficient research on the high-temperature mechanical properties of deep rocks in southwestern China, we used high-temperature heating devices and statics equipment to conduct static tests on Skarn. XW7L-12 box-type resistance furnace was adopted to heat Skarn $\left(25^{\circ} \mathrm{C}, 200^{\circ} \mathrm{C}, 400^{\circ} \mathrm{C}, 600^{\circ} \mathrm{C}\right.$, and $\left.800^{\circ} \mathrm{C}\right)$, and the temperature effect of its basic physical parameters (density and wave velocity) was measured and analyzed. Uniaxial compression experiments were performed on two cooling methods of Skarn (natural cooling and water cooling) by a constant stress pressure testing machine to obtain a stress-strain curve and analyze its statics index (peak strength, tensile strength, elastic modulus, and peak strain) and the change rule of failure mode with temperature rise and different cooling methods. With the temperature increasing, various static mechanical indexes of Skarn will be greatly affected. Meanwhile, the different cooling methods are not related to the change trend of the mechanical properties of Skarn under high temperature.

\section{Introduction}

With the increasing shortage of surface land resources and the continuous development of shallow underground energy, developing deep underground space is becoming more and more important. The comprehensive development of new resources in underground ecological urban space is an important measure to solve the three major crises of urban population, resources, and environment. At present, many countries have reconstructed and used underground goafs as human living and working places. For example, the United States once converted an old mine with a depth of 2,000 meters underground into a laboratory; France built the Haute Marne laboratory 500 meters underground to store nuclear waste; Japan's Shiroyama Underground Hydropower Station was built at a depth of 200 meters underground; the sewage treatment plant under the Helsinki Base in Finland is located at a depth of 100 meters underground [1-4]. As an excellent natural protective material, natural rock has the advantages of hard texture, high carrying capacity, and good durability [5]. In response to underground buildings encountering fires, military strikes, and rock engineering reconstruction after fires, the study of the mechanical properties of deep rocks at high temperatures has risen to a height related to national security and strategy.

In the process of deep mining, high ground stress, high ground temperature, high seepage water pressure, and mining disturbance make the underground engineering environment extremely complicated [6]. Deep rocks not only have to withstand the unusually variable temperature environment but also suffer from various dynamic 
disturbance loads. Sudden major disasters such as rock bursts, mine fires, and gas outbursts often occur in the process of deep rock mining; meanwhile, rock bursts often occur during blasting operations in hydropower stations, metal deposits, and traffic tunnels. These disasters have caused a great threat to the life safety of the front-line production engineers and also greatly increased the construction cost. Whether it is engineering disasters caused by deep rock mining or underground protection projects, they all involve the mechanical properties of rocks under high temperatures. Therefore, the study of high-temperature mechanical properties of rocks is of great significance to the development of underground engineering in the future.

In recent years, the research team plans to conduct high-temperature experimental research on Skarn, which is common in deep mining in China's Yunnan-Guizhou Plateau. Therefore, the paper intends to use high-temperature heating devices and static test equipment to conduct static experimental research on Skarn specimens after high temperature and to explore the changes between the mechanical properties of Skarn, temperature, cooling method, and load.

\section{Literature Review}

Temperature is one of the important factors that affect the change of material properties. The effect of high temperature can change the internal structure and mineral composition of the rock, which in turn changes the performance of the rock. Eventually, the performance of the rock undergoing high-temperature action is very different from that of the rock at room temperature. According to the different hightemperature heating treatment methods, there are three types of high-temperature heating methods for the specimen. The first is to locally heat the test piece, that is, only heat the test piece. $\mathrm{Wu}$ et al. [7, 8] adopt the method of only heating the test piece separately to obtain the dynamic mechanical properties of the material at high temperature. This method avoids the contact time of the pressure rod and the high-temperature test piece, but it cannot avoid the uniform distribution and loss of the specimen heat during the impact process. The second method adopts the isolation block method, that is, put an isolation block on both ends of the test piece. $\mathrm{Wu}$ et al. [7,9] used alumina ceramic as a spacer to study the dynamic antistress performance of the material at $1500^{\circ} \mathrm{C}$. The third is to put the pressure rod and the test block into a high-temperature furnace for heating. Djapic Oosterkamp [10] used this experimental method to study the dynamic mechanical properties of aluminum alloy at $515^{\circ} \mathrm{C}$. Considering that this heating method will affect the elastic rod, it limits the range of experimental temperature to a large extent.

At present, many scholars have explored the influence of temperature effects on rock physical parameters and mechanical properties through experimental methods and then obtained many changing laws of mechanical indicators such as wave velocity, crack, compressive strength, elastic modulus, and failure mode. In 1981, Van der Molen [11] heated granite under high confining pressure from room temperature to $900^{\circ} \mathrm{C}$. It was discovered that quartz, the main mineral component of granite, would undergo phase change during the heating process and would affect the changes in the mechanical properties of granite. In 1998, Mahmutoglu [12] carried out a cyclic heating experiment on sandstone, in which the number of heating was $0-16$ times and the temperature was set at $0-600^{\circ} \mathrm{C}$. Through the analysis of the experimental results, as the heating period continues to increase, the mechanical properties of the rock gradually decrease, the compressive strength decreases by about $50 \%$, the tensile strength decreases by about $60 \%$, and the stress-strain curve before and after heating does not change much. Ferrero and Marini [13] conducted high-temperature tests on different types of marble and compared the effects of temperature on the properties and thermal cracking of the two materials. Studies have shown that the modulus of the two types of rocks decreases, but the decrease of black marble is larger than that of white marble, and the sensitivity of crack density to different types of marble is also different under the action of temperature. Xu [14] used the MTS810 electrohydraulic servo material experimental system to conduct experimental research on granite samples under real-time high temperature. The peak strength and elastic modulus of granite can be divided into 4 stages with increasing temperature: $25 \sim 200^{\circ} \mathrm{C}$ is the slow growth stage; $200 \sim 600^{\circ} \mathrm{C}$ is the rapid decline stage; $600 \sim 800^{\circ} \mathrm{C}$ is the slow rise stage; and $800 \sim 100^{\circ} \mathrm{C}$ is the gentle decline stage. The peak strain of granite decreases with increasing temperature in the range of $25 \sim 600^{\circ} \mathrm{C}$ and increases with increasing temperature after $600^{\circ} \mathrm{C}$, and there is a cubic polynomial fitting relationship with temperature. With the increase of temperature, the deformation failure mode of granite changes from tensile-shear failure to conical failure, and the form of instability changes from sudden instability to progressive failure. Through uniaxial compression experiments, Liu et al. [15-17] conducted uniaxial compression experiments to study the temperature effects of marble treated at different temperatures, including wave speed, compressive strength, failure mode, and damage characteristics. The experimental results show that the failure mode of marble after high temperature is mainly splitting, and the wave velocity and compressive strength will decrease with the increase of temperature, and the damage factor will increase with the increase of temperature, which all indicate that the internal damage occurred in the marble after high temperature. The above phenomenon illustrates the fact that the internal damage occurs in marble after high temperature. Dong et al. [18] discussed the mechanical properties of granite under cyclic heating and rapid cooling conditions through uniaxial compression tests and Brazilian disc splitting experiments. Under the combined action of temperature $\left(250 \sim 650^{\circ} \mathrm{C}\right)$ increase and cycle times (0 20 times) of granite specimens, the mechanical properties of granite specimens gradually deteriorate and the specimens undergo a transition from brittleness to plasticity. The state of failure changes from a typical split mode to flake or massive exfoliation.

In the following sections, after a brief literature review, we first introduce the influence of temperature on rock mechanical properties. Next, in the third section, we describe the static test method of Skarn in high temperature. Then, we present experimental results in the fourth section. 
In the fifth section, we present the result analysis of two cooling methods. Finally, we discuss the results and derive conclusions.

\section{High-Temperature Static Test Method}

The statics test consists of Skarn uniaxial compression test and Skarn Brazilian disc split test after high temperature. The uniaxial compression experiment can be divided into the compression experiment after natural cooling and the uniaxial compression experiment after cooling by cold water.

3.1. Experimental Scheme. The size of the uniaxial compression test specimen is $\varphi 50 \times 100 \mathrm{~mm}$, and according to references [19-21] in the citation, the size of the Brazil disc split test specimen is $\varphi 50 \times 40 \mathrm{~mm}$. The central angle of the test piece $2 a=20^{\circ}$. According to references $[14,15]$ in the citation, the following temperature gradient is selected: $25^{\circ} \mathrm{C}$, $200^{\circ} \mathrm{C}, 400^{\circ} \mathrm{C}, 600^{\circ} \mathrm{C}$, and $800^{\circ} \mathrm{C}$, and each group performed 3 parallel experiments.

3.2. Experiment Apparatus. The XW7L-12 box-type resistance furnace equipment is used for the high-temperature heating and preservation of the Skarn test piece, as shown in Figure 1. The maximum working temperature of this equipment can reach $1200^{\circ} \mathrm{C}$. In order to prevent rock specimen from reacting with external water vapor, the cooled Skarn specimen is placed in the Tester WGLL-230BE electric heating blast drying box for dry storage, as shown in Figure 2. The equipment uses a temperature range of $10 \sim 300^{\circ} \mathrm{C}$. The uniaxial compression experiment of Skarn after cooling was completed on the YAW-2000C constant stress compression testing machine, as shown in Figure 3. The maximum test force of the equipment is $2000 \mathrm{kN}$, the test force range is $0 \sim 2000 \mathrm{kN}$, the rated voltage is $380 \mathrm{~V} /$ $220 \mathrm{~V}$, the working environment temperature is $10 \sim 35^{\circ} \mathrm{C}$, and the working environment should be vibration-free and noncorrosive, in an environment without magnetic field interference. Figure 4 shows the size of the Skarn specimen in the Brazilian disc experiment.

The Brazilian disc splitting experiment was completed on the RFP-03 intelligent dynamometer, as shown in Figure 5. The rated voltage of the equipment is $380 \mathrm{~V}$, the measuring range is $50 \sim 3000 \mathrm{kN}$, the working environment temperature is $-10 \sim 40^{\circ} \mathrm{C}$, and the working environment humidity is $30 \%-80 \%$.

3.3. Notes on Statics Test. In order to reduce the experimental error and improve the accuracy of the experiment, corresponding optimization measures have been taken during the operation of the high-temperature statics experiment, and the following issues should be paid attention to:

(1) In the process of high-temperature treatment of Skarn rock, in order to ensure that the inside and outside of the test piece is heated evenly and fully, the heating rate is uniformly set to $10^{\circ} \mathrm{C} / \mathrm{min}$, the

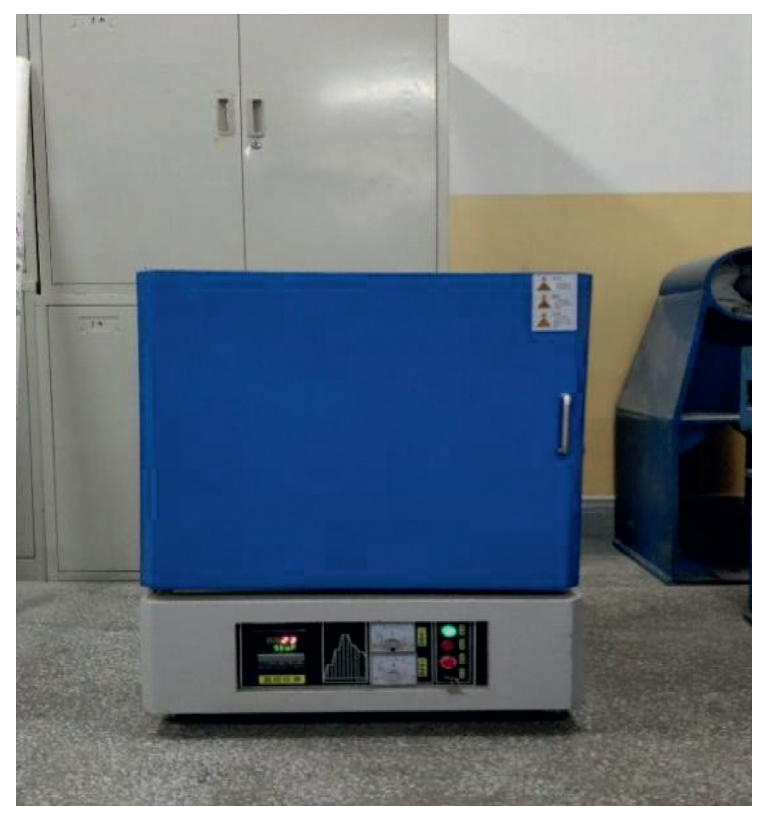

FIgURE 1: Box-type resistance furnace.



FIGURE 2: Electric heating blast drying oven.

constant temperature time is 2 hours, and the cooling method is set to natural cooling and water cooling. After being cooled to room temperature, it is stored in an electric blast drying box.

(2) The loading control method of statics experiment equipment adopts stress control. According to the requirements of "Engineering Rock Mass Experimental Method Standard," the loading control method of statics test equipment adopts stress control, and the loading rate is uniformly controlled to $0.5 \mathrm{MPa} / \mathrm{s}$. Meanwhile, the rate also meets the requirements of uniaxial compression test and tensile test. 


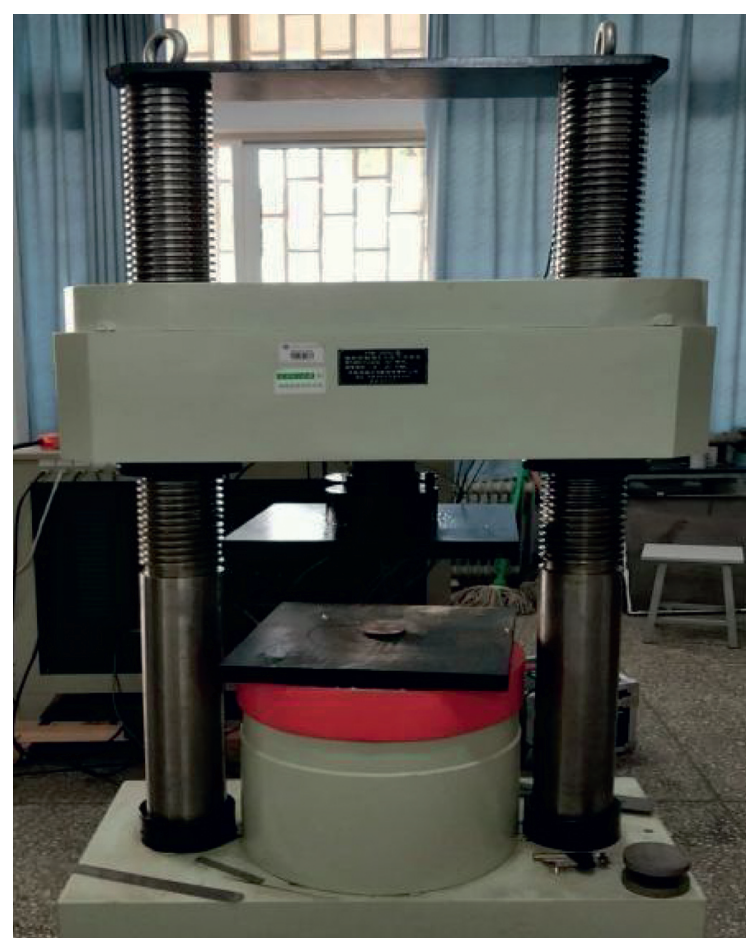

Figure 3: The YAW-2000C constant stress compression testing machine.

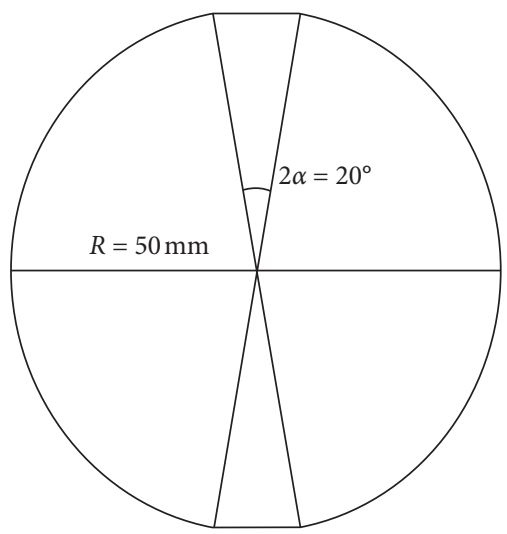

FIgURE 4: Schematic diagram of the split specimen.

(3) Before the uniaxial compression experiment, in order to reduce the influence of the end face restraint effect of the rock specimen on the compressive strength of the rock specimen in the static experiment, lubricating oil can be applied to both ends of the specimen.

(4) In the Brazilian disc splitting experiment, in order to reduce the stress concentration effect between the test block and the rod, the rock test piece used for this part was uniformly processed into a test piece with a central angle of $2 a=20^{\circ}$ and constant diameter and height.

(5) After the end of the experiment, the fragments of the damaged specimen should be collected and photographed for the analysis of the failure type of the

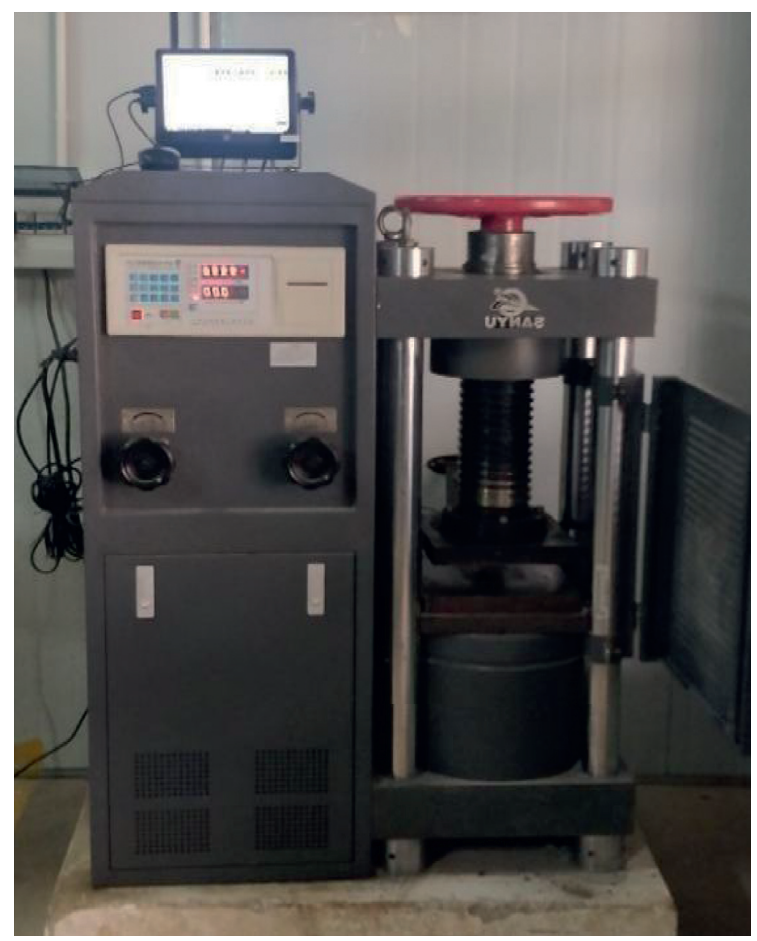

Figure 5: RFP-03 intelligent dynamometer.

specimen and the characteristic study of the microscopic failure mechanism.

\section{Experimental Results and Stress-Strain Curve}

4.1. Experimental Result Display. The experimental data of air cooling and water cooling static load compression and Brazilian disc splitting experiment are shown in Tables 1-4, respectively.

4.2. Stress-Strain Curve Analysis. The stress-strain curves of the uniaxial compression experiment of Skarn natural and water cooling after high temperature are shown in Figures 6 and 7 , respectively.

The analysis shows that the stress-strain curves of different cooling methods under the same temperature conditions are similar in shape, indicating that the cooling method has little effect on the shape of the Skarn stressstrain curve after high temperature. But in the same cooling method Under the premise of, the Skarn stress-strain curve shape difference after different temperature $\left(25^{\circ} \mathrm{C} \sim 800^{\circ} \mathrm{C}\right)$ treatments is obvious, indicating that the temperature effect is the main reason for the difference of the Skarn stressstrain curve shape.

The stress-strain curve corresponding to $25^{\circ} \mathrm{C}$ before reaching the peak stress can be regarded as a straight line. After reaching the peak stress, the curve drops rapidly, indicating that the specimen suddenly breaks and loses compressive bearing capacity.

The stress-strain curves before the peaks at $200^{\circ} \mathrm{C}$, $400^{\circ} \mathrm{C}$, and $600^{\circ} \mathrm{C}$ are roughly similar in shape and can be divided into three stages: firstly, a concave curve, which is 
TABLE 1: Uniaxial compression test data (natural cooling).

\begin{tabular}{|c|c|c|c|c|c|c|c|}
\hline $\begin{array}{l}\text { Specimen } \\
\text { number }\end{array}$ & $\begin{array}{c}\text { Temperature } \\
\left({ }^{\circ} \mathrm{C}\right)\end{array}$ & $\begin{array}{l}\text { Diameter } \\
(\mathrm{mm})\end{array}$ & $\begin{array}{l}\text { Height } \\
(\mathrm{mm})\end{array}$ & $\begin{array}{l}\text { Quality } \\
\text { (g) }\end{array}$ & $\begin{array}{c}\text { Compressive strength } \\
(\mathrm{MPa})\end{array}$ & $\begin{array}{c}\text { Elastic modulus } \\
(\mathrm{GPa})\end{array}$ & $\begin{array}{l}\text { Peak strain } \\
(\mu \varepsilon)\end{array}$ \\
\hline YKL-1 & 25 & 50 & 100 & 648 & 250.19 & 82.01 & 3244 \\
\hline YKL-2 & 25 & 50 & 100 & 660 & 260.17 & 83.65 & 3601 \\
\hline YKL-3 & 25 & 50 & 100 & 651 & 242.70 & 79.40 & 3565 \\
\hline YKL-4 & 200 & 50 & 100 & 657 & 250.89 & 52.82 & 5086 \\
\hline YKL-5 & 200 & 50 & 100 & 660 & 243.33 & 53.66 & 5449 \\
\hline YKL-6 & 200 & 50 & 100 & 652 & 262.64 & 49.93 & 5273 \\
\hline YKL-7 & 400 & 50 & 100 & 651 & 176.69 & 30.57 & 4220 \\
\hline YKL-8 & 400 & 50 & 100 & 650 & 181.83 & 30.98 & 5706 \\
\hline YKL-9 & 400 & 50 & 100 & 646 & 180.64 & 33.65 & 5865 \\
\hline YKL-10 & 600 & 50 & 100 & 656 & 118.46 & 16.14 & 6430 \\
\hline YKL-11 & 600 & 50 & 100 & 649 & 97.10 & 18.33 & 6718 \\
\hline YKL-12 & 600 & 50 & 100 & 662 & 102.66 & 14.79 & 6001 \\
\hline YKL-13 & 800 & 50 & 100 & 651 & 52.88 & 4.17 & 13880 \\
\hline YKL-14 & 800 & 50 & 100 & 662 & 62.40 & 4.91 & 13205 \\
\hline YKL-15 & 800 & 50 & 100 & 658 & 50.39 & 4.04 & 14021 \\
\hline
\end{tabular}

Note. YKL represents the specimen used for the uniaxial compression experiment after air cooling.

TABLE 2: Uniaxial compression test data (water cooling).

\begin{tabular}{|c|c|c|c|c|c|c|c|}
\hline $\begin{array}{l}\text { Specimen } \\
\text { number }\end{array}$ & $\begin{array}{c}\text { Temperature } \\
\left({ }^{\circ} \mathrm{C}\right)\end{array}$ & $\begin{array}{l}\text { Diameter } \\
(\mathrm{mm})\end{array}$ & $\begin{array}{l}\text { Height } \\
(\mathrm{mm})\end{array}$ & $\begin{array}{l}\text { Quality } \\
\text { (g) }\end{array}$ & $\begin{array}{c}\text { Compressive strength } \\
(\mathrm{MPa})\end{array}$ & $\begin{array}{c}\text { Elastic modulus } \\
(\mathrm{GPa})\end{array}$ & $\begin{array}{l}\text { Peak strain } \\
(\mu \varepsilon)\end{array}$ \\
\hline YSL-1 & 25 & 50 & 100 & 653 & 250.19 & 82.01 & 3244 \\
\hline YSL-2 & 25 & 50 & 100 & 662 & 260.17 & 83.65 & 3601 \\
\hline YSL-3 & 25 & 50 & 100 & 656 & 242.70 & 79.40 & 3565 \\
\hline YSL-4 & 200 & 50 & 100 & 649 & 236.35 & 51.45 & 4059 \\
\hline YSL-5 & 200 & 50 & 100 & 653 & 232.02 & 56.84 & 4190 \\
\hline YSL-6 & 200 & 50 & 100 & 660 & 237.42 & 44.28 & 3927 \\
\hline YSL-7 & 400 & 50 & 100 & 670 & 136.21 & 23.16 & 5930 \\
\hline YSL-8 & 400 & 50 & 100 & 662 & 125.64 & 20.04 & 6337 \\
\hline YSL-9 & 400 & 50 & 100 & 659 & 147.78 & 26.73 & 5620 \\
\hline YSL-10 & 600 & 50 & 100 & 655 & 110.31 & 9.76 & 9110 \\
\hline YSL-11 & 600 & 50 & 100 & 668 & 108.22 & 10.11 & 9210 \\
\hline YSL-12 & 600 & 50 & 100 & 663 & 115.31 & 9.94 & 9394 \\
\hline YSL-13 & 800 & 50 & 100 & 660 & 32.28 & 1.59 & 13740 \\
\hline YSL-14 & 800 & 50 & 100 & 672 & 38.70 & 1.37 & 14371 \\
\hline YSL-15 & 800 & 50 & 100 & 668 & 33.91 & 1.83 & 13277 \\
\hline
\end{tabular}

Note. YSL represents the specimen used for the uniaxial compression experiment after water cooling.

TABLE 3: Brazilian disc splitting experiment test data (natural cooling).

\begin{tabular}{|c|c|c|c|c|c|c|c|}
\hline $\begin{array}{l}\text { Specimen } \\
\text { number }\end{array}$ & $\begin{array}{c}\text { Temperature } \\
\left({ }^{\circ} \mathrm{C}\right)\end{array}$ & $\begin{array}{c}\text { Diameter } \\
(\mathrm{mm})\end{array}$ & $\begin{array}{c}\text { Thickness } \\
(\mathrm{mm})\end{array}$ & $\begin{array}{c}\text { Quality } \\
(\mathrm{g})\end{array}$ & $\begin{array}{c}\text { Failure load } \\
(\mathrm{kN})\end{array}$ & $\begin{array}{c}\text { Tensile strength } \\
(\mathrm{MPa})\end{array}$ & $\begin{array}{c}\text { Average value } \\
(\mathrm{MPa})\end{array}$ \\
\hline LKL-1 & 25 & 50 & 40.45 & 275 & 44.13 & 11.12 & \\
\hline LKL-2 & 25 & 50 & 40.00 & 268 & 66.58 & 16.96 & 14.27 \\
\hline LKL-3 & 25 & 50 & 40.20 & 256 & 58.14 & 14.74 & \\
\hline LKL-4 & 200 & 50 & 40.70 & 280 & 35.56 & 8.90 & \\
\hline LKL-5 & 200 & 50 & 40.60 & 266 & 34.56 & 8.68 & 8.88 \\
\hline LKL-6 & 200 & 50 & 39.9 & 245 & 35.44 & 9.05 & \\
\hline LKL-7 & 400 & 50 & 41.4 & 282 & 28.86 & 7.10 & \\
\hline LKL-8 & 400 & 50 & 40 & 275 & 28.8 & 7.34 & 7.05 \\
\hline LKL-9 & 400 & 50 & 40 & 265 & 26.38 & 6.72 & \\
\hline LKL-10 & 600 & 50 & 40.8 & 255 & 20.26 & 5.06 & \\
\hline LKL-11 & 600 & 50 & 41.4 & 271 & 22.40 & 5.51 & 5.37 \\
\hline LKL-12 & 600 & 50 & 40.1 & 267 & 21.76 & 5.53 & \\
\hline LKL-13 & 800 & 50 & 41 & 267 & 14.61 & 3.63 & \\
\hline LKL-14 & 800 & 50 & 39.7 & 246 & 13.54 & 3.48 & 3.64 \\
\hline LKL-15 & 800 & 50 & 40.4 & 282 & 15.06 & 3.80 & \\
\hline
\end{tabular}

Note. LKL represents the test piece used for Brazilian disc splitting experiment after air cooling. 
TABLE 4: Brazilian disc splitting experiment test data (water cooling).

\begin{tabular}{|c|c|c|c|c|c|c|c|}
\hline $\begin{array}{l}\text { Specimen } \\
\text { number }\end{array}$ & $\begin{array}{c}\text { Temperature } \\
\left({ }^{\circ} \mathrm{C}\right)\end{array}$ & $\begin{array}{c}\text { Diameter } \\
(\mathrm{mm})\end{array}$ & $\begin{array}{c}\text { Thickness } \\
(\mathrm{mm})\end{array}$ & $\begin{array}{c}\text { Quality } \\
(\mathrm{g})\end{array}$ & $\begin{array}{c}\text { Failure load } \\
(\mathrm{kN})\end{array}$ & $\begin{array}{c}\text { Tensile strength } \\
(\mathrm{MPa})\end{array}$ & $\begin{array}{c}\text { Average value } \\
(\mathrm{MPa})\end{array}$ \\
\hline LSL-1 & 25 & 50 & 40.45 & 275 & 44.13 & 11.12 & \\
\hline LSL-2 & 25 & 50 & 40.00 & 268 & 66.58 & 16.96 & 14.27 \\
\hline LSL-3 & 25 & 50 & 40.20 & 256 & 58.14 & 14.74 & \\
\hline LSL-4 & 200 & 50 & 40.40 & 274 & 22.91 & 7.22 & \\
\hline LSL-5 & 200 & 50 & 39.12 & 262 & 32.83 & 8.55 & 7.43 \\
\hline LSL-6 & 200 & 50 & 40.80 & 268 & 26.14 & 6.53 & \\
\hline LSL-7 & 400 & 50 & 41.30 & 273 & 13.50 & 4.16 & \\
\hline LSL-8 & 400 & 50 & 41.40 & 268 & 37.75 & 9.29 & 6.04 \\
\hline LSL-9 & 400 & 50 & 40.70 & 269 & 18.70 & 4.68 & \\
\hline LSL-10 & 600 & 50 & 41.10 & 278 & 18.70 & 5.80 & \\
\hline LSL-11 & 600 & 50 & 41.20 & 272 & 22.86 & 5.65 & 5.49 \\
\hline LSL-12 & 600 & 50 & 41.30 & 280 & 20.31 & 5.01 & \\
\hline LSL-13 & 800 & 50 & 40.90 & 275 & 15.82 & 4.93 & \\
\hline LSL-14 & 800 & 50 & 41.50 & 270 & 0 & 0 & 3.6 \\
\hline LSL-15 & 800 & 50 & 41.10 & 267 & 9.17 & 2.27 & \\
\hline
\end{tabular}

Notes. LSL represents the test piece used for Brazilian disc splitting experiment after water cooling. The data "0" indicates that the specimen has been damaged during heating or cooling.

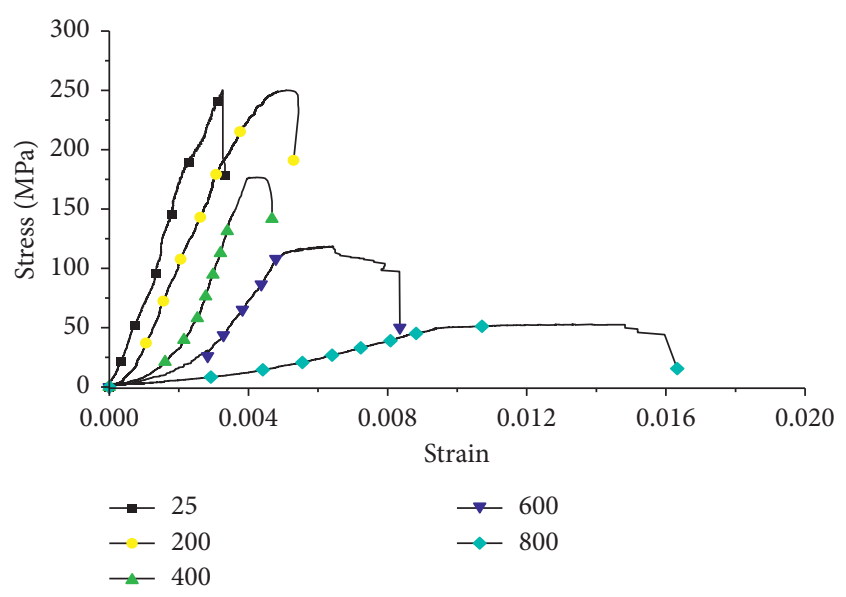

FIGURE 6: Stress-strain curve of uniaxial compression test (natural cooling).

the process of compacting the microcracks inside the Skarn rock; secondly, it is an approximately straight curve, when the cracks inside the rock are in a stable development stage; after that, the curve grows slowly and rises upward, indicating that the crack growth inside the rock is extremely unstable at this stage. In the last stage, after reaching the peak stress, the strain continues to increase, and the stress drops rapidly, indicating that the Skarn specimen has been damaged.

Compared with other curves $\left(25^{\circ} \mathrm{C}, 200^{\circ} \mathrm{C}, 400^{\circ} \mathrm{C}\right.$, and $600^{\circ} \mathrm{C}$ ), the stress-strain curve corresponding to $800^{\circ} \mathrm{C}$ includes internal crack compaction stage, linear elastic stage, unstable crack development stage, and rock failure and instability stage. There is an extra linear stage almost parallel to the $x$-axis, that is, as the strain increases, the stress no longer increases, and the peak strain at this time is also significantly greater than other temperatures $\left(25^{\circ} \mathrm{C}, 200^{\circ} \mathrm{C}\right.$, $400^{\circ} \mathrm{C}$, and $600^{\circ} \mathrm{C}$ ). Skarn becomes more and more "soft"

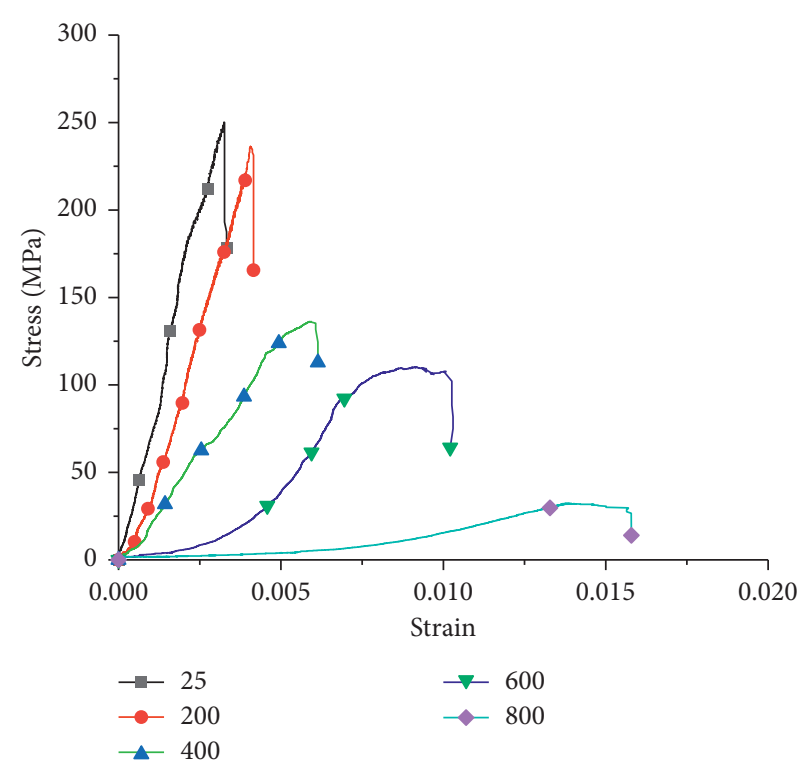

FIgURE 7: Stress-strain curve of uniaxial compression test (water cooling).

after being heated at a high temperature above $800^{\circ} \mathrm{C}$, and the ductility is significantly enhanced.

\section{Temperature Effect of Different Cooling Methods on Static Properties of Skarn}

5.1. Peak Stress Variation Rule. The peak stress (uniaxial compressive strength) of the Skarn rock is the maximum compressive stress that the Skarn can withstand before failure under uniaxial compression load, or called unrestricted compressive strength.

The relationship between the compressive strength and temperature of Skarn after natural cooling and water cooling 
is shown in Figure 8. After fitting, it is found that there is a linear function relationship between peak stress and temperature. The fitting formula is shown in equation (1), and Table 5 is the parameter table of the fitting formula.

$$
\sigma=a x+b
$$

where $\sigma$ is the peak stress of the Skarn specimen and $a$ and $b$ are the coefficients of the fitting formula.

Figure 8(a) represents natural cooling and Figure 8(b) represents water cooling. The temperature range of the two cooling methods rises from room temperature $25^{\circ} \mathrm{C}$ to $800^{\circ} \mathrm{C}$. Although the cooling method is different, the change trend of the peak stress is the same. According to the experimental results, $200^{\circ} \mathrm{C}$ has almost no effect on the compressive strength of Skarn rock. When the temperature reaches $400^{\circ} \mathrm{C}$, the relative decrease of the compressive strength reaches the maximum. Water cooling has a greater impact on the rock than natural cooling. Therefore, it shows that $400^{\circ} \mathrm{C}$ is the temperature threshold for the decrease of Skarn compressive strength, after which the compressive strength of Skarn will be greatly reduced. When the temperature rises to $800^{\circ} \mathrm{C}$, the peak stress reduction of Sharn rock reaches the maximum, and the degradation of the compressive strength caused by the temperature effect reaches the maximum, indicating that the reduction of the compressive strength will continue to expand with the increase of temperature. The peak stress rate of change with temperature is shown in Table 6.

5.2. Elastic Modulus Variation Rule. Rock elastic modulus refers to the ratio of stress to strain in the elastic range. Since the stress-strain curve of most rocks is composed of pore fracture compaction stage, fracture stable development stage, unstable rupture stage, and postrupture stage, there is an elastic modulus value for each point on the curve. Thus, the elastic modulus of Skarn mentioned in this paper is the secant modulus, which is the slope of the secant line at the origin of the stress-strain curve and the $50 \%$ point of the peak strength. The relationship between the elastic modulus and temperature of the cooled Skarn is shown in Figure 9 (Figure 9(a) represents natural cooling and Figure 9(b) represents water cooling). After fitting, it is found that there is an exponential function relationship between elastic modulus and temperature. The fitting formula is shown in equation (2), and Table 7 is the parameter table of the fitting formula.

$$
E=a \times e^{-(T / b)}+c,
$$

where $E$ is the elastic modulus of the Skarn specimen, $T$ is temperature, and $a, b$, and $c$ are the coefficients of the fitting formula.

The changing law of elastic modulus is the same as that of peak stress. As the temperature increases, the elastic modulus of Skarn gradually decreases. And as the temperature rises, the drop will continue to expand, as shown in Figure 9. Similarly, the cooling method has no effect on the change trend of the elastic modulus of Skarn, and only water cooling has a slightly greater influence on the elastic modulus than air cooling. Table 8 shows the change rate of elastic modulus of Skarn with temperature.

5.3. Peak Strain Change Law. The change law of the Skarn peak strain after high-temperature cooling is shown in Figure 10. After fitting, it is found that there is an exponential function relationship between peak strain and temperature, and the peak strain should be less affected by the cooling method. The fitting formula is shown in equation (3), and Table 9 is the parameter table of the fitting formula.

$$
\varepsilon=a \times e^{T / b}+c
$$

where $\varepsilon$ is the peak strain of the Skarn specimen, $T$ is temperature, and $a, b$, and $c$ are the coefficients of the fitting formula.

In Figure 10, as the temperature increases, the peak strain of Skarn gradually increases. However, between $200^{\circ} \mathrm{C}$ and $400^{\circ} \mathrm{C}$, the change rule of the peak strain of natural cooling reverses. The peak strain at $200^{\circ} \mathrm{C}$ is greater than the peak strain at $400^{\circ} \mathrm{C}$, and then the peak strain increases sharply. The peak strain of Skarn reaches its maximum at $800^{\circ} \mathrm{C}$. The peak value of water cooling should increase with increasing temperature, and the curve should be smoother. Table 9 shows the variation of Skarn peak strain with increasing temperature.

5.4. Tensile Strength Change Law. The force of failure of the Skarn specimen in the Brazilian disc experiment was obtained by the RFP-03 intelligent dynamometer. The specimen with split failure along the diameter was selected, and combined with formula (4) and the correction formula of tensile strength (5), the tensile strength of Skarn can be obtained. The fitting formula is shown in equation (6), and Table 10 is the parameter table of the fitting formula.

$$
\begin{gathered}
\sigma_{t}=\frac{2 p}{\pi \mathrm{DH}}, \\
\sigma_{t}=\delta \frac{2 p}{\pi \mathrm{DH}},
\end{gathered}
$$

where $P$ is the maximum pressure value $(\mathrm{kN})$ when the specimen is split and damaged, $D$ is the diameter $(m)$ of the specimen, $\mathrm{H}$ is the height $(\mathrm{m})$ of the specimen, and $\delta$ is the correction factor considering the loading of the platform.

$$
\sigma_{t}=a \times e^{-(T / b)}+c,
$$

where $\sigma_{t}$ is the tensile strength of the Skarn specimen, $T$ is temperature, and $a, b$, and $c$ are the coefficients of the fitting formula.

From Figure 11 and Table 10, it can be seen that the tensile strength of Skarn after high temperature and natural cooling is significantly higher than that after water cooling, indicating that the cooling method has an influence on the static tensile strength of Skarn, but this difference causes the influence of the temperature is already apparent at $200^{\circ} \mathrm{C}$. 


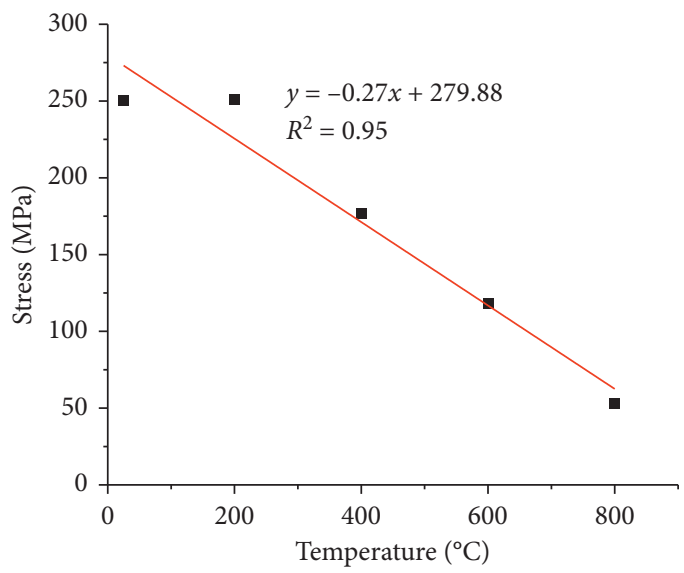

(a)

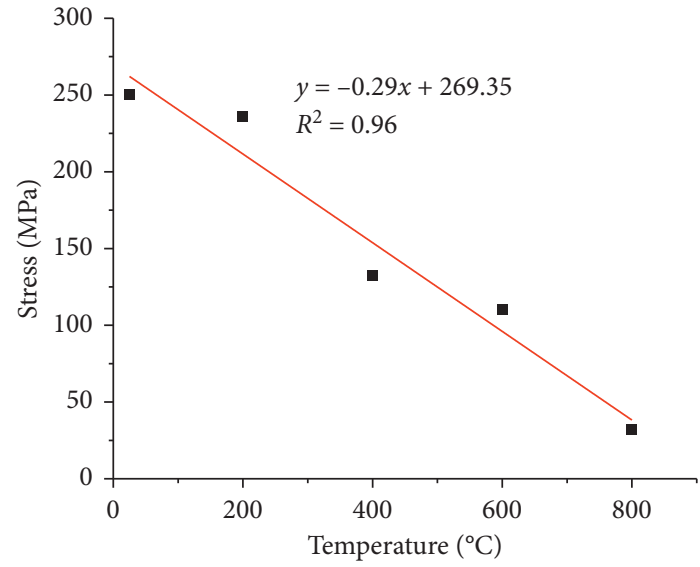

(b)

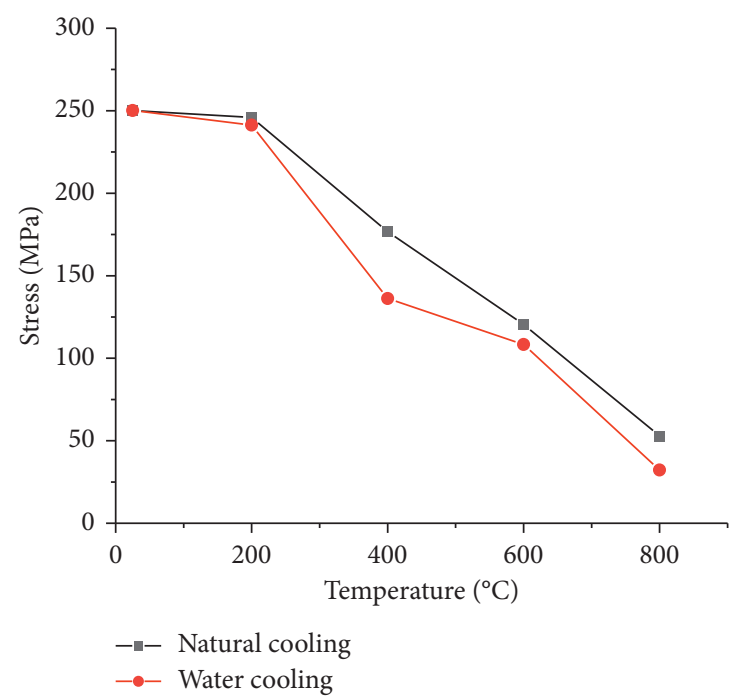

(c)

FIGURE 8: Relationship between peak stress and temperature (natural cooling and water cooling). (a) Natural cooling; (b) water cooling; (c) effect of cooling mode on peak stress of Skarn.

TABLE 5: Fitting formula parameter table (natural cooling and water cooling).

\begin{tabular}{lccc}
\hline Rock & $a$ & $b$ & $R^{2}$ \\
\hline Skarn (natural cooling) & -0.27 & 279.88 & 0.95 \\
Skarn (water cooling) & -0.29 & 269.35 & 0.96 \\
\hline
\end{tabular}

TABLE 6: Peak stress rate of change with temperature.

\begin{tabular}{lccccc}
\hline Temperature & $25^{\circ} \mathrm{C}(\%)$ & $200^{\circ} \mathrm{C}(\%)$ & $400^{\circ} \mathrm{C}(\%)$ & $600^{\circ} \mathrm{C}(\%)$ & $800^{\circ} \mathrm{C}(\%)$ \\
\hline Natural cooling & 100 & 99.72 & 70.62 & 47.35 & 21.14 \\
Water cooling & 100 & 94.47 & 54.44 & 44.09 & 12.90 \\
\hline
\end{tabular}

During the heating process of $200 \sim 800^{\circ} \mathrm{C}$, the two curves have never overlapped. The tensile strength curve of air cooling has always been above the water cooling curve, indicating that water cooling is compared with natural cooling. The cooling method has a degrading effect on the strength of Skarn. 




(a)



(b)

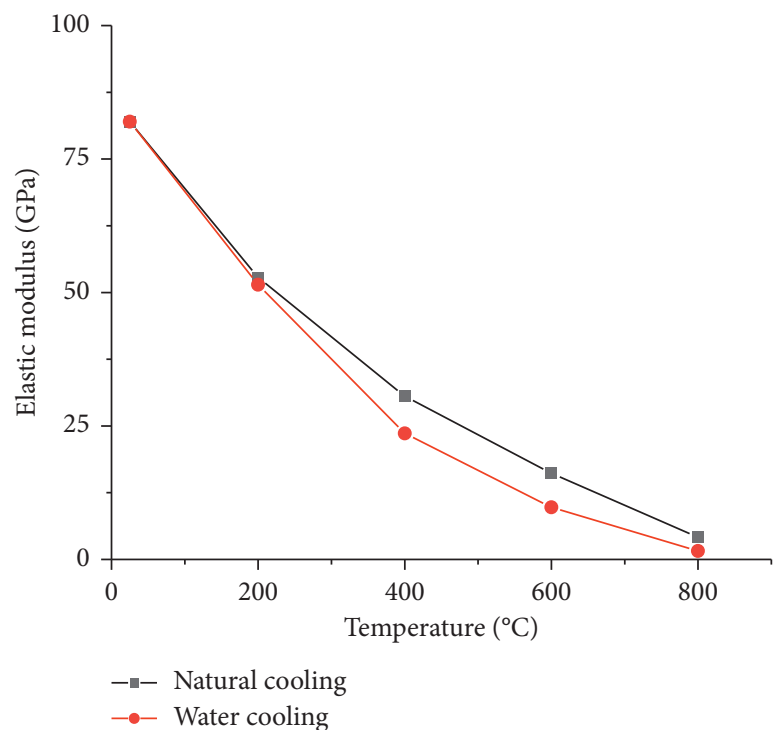

(c)

FIGURE 9: Relationship between elastic modulus and temperature (natural cooling and water cooling). (a) Natural cooling; (b) water cooling; (c) effect of cooling mode on elastic modulus.

TABLE 7: Fitting formula parameter table (natural cooling and water cooling).

\begin{tabular}{lccrr}
\hline Rock & $a$ & $b$ & $c$ & $R^{2}$ \\
\hline Skarn (natural cooling) & 104.28 & 518.86 & -17.59 & 0.99 \\
Skarn (water cooling) & 102.73 & 414 & -14.04 & 0.99 \\
\hline
\end{tabular}

TABle 8: Peak stress rate of change with temperature.

\begin{tabular}{lccccc}
\hline Temperature & $25^{\circ} \mathrm{C}(\%)$ & $200^{\circ} \mathrm{C}(\%)$ & $400^{\circ} \mathrm{C}(\%)$ & $600^{\circ} \mathrm{C}(\%)$ & $800^{\circ} \mathrm{C}(\%)$ \\
\hline Natural cooling & 100 & 64.41 & 37.28 & 19.68 & 5.08 \\
Water cooling & 100 & 62.74 & 28.24 & 11.90 & 1.94 \\
\hline
\end{tabular}

\section{Failure Mode of Skarn Specimen}

The uniaxial compression test failure morphology of the Skarn specimen is shown in Figure 12.

In Figure 12, the failure of the Skarn specimen under uniaxial compression load is mainly in the form of shear failure, and the shear failure surface is in the shape of "I," "V," and "X." As the temperature increases, the visible cracks on the specimen gradually increase. Most of the damage of the specimens occurs along the visible cracks and joint planes, and the integrity of the specimens after failure is better with the increase of temperature.

The damage pattern of the Brazilian disc splitting experiment of Skarn is shown in Figure 13.

In Figure 13, the Skarn specimens all crack and fail along the diameter direction from the center, which meets the 


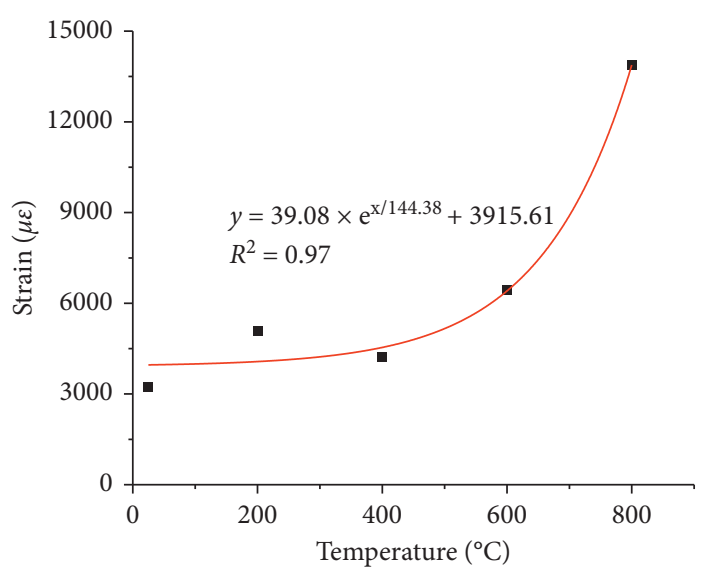

(a)

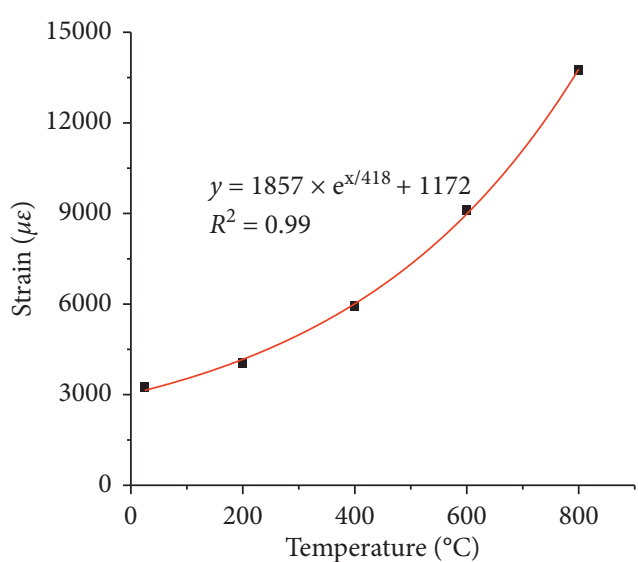

(b)



(c)

FIGURE 10: Relationship between strain and temperature (natural cooling and water cooling). (a) Natural cooling; (b) water cooling; (c) effect of cooling mode on peak strain of Skarn.

TABLE 9: Fitting formula parameter table (natural cooling and water cooling).

\begin{tabular}{lccrr}
\hline Rock & $a$ & $b$ & $c$ & $R^{2}$ \\
\hline Skarn (natural cooling) & 39.08 & 144.38 & 3915.61 & 0.97 \\
Skarn (water cooling) & 1857 & 418 & 11 & 0.99 \\
\hline
\end{tabular}

Table 10: Parameter table of fitting formula.

\begin{tabular}{lccrr}
\hline Rock & $a$ & $b$ & $c$ & $R^{2}$ \\
\hline Skarn (natural cooling) & 21.31 & 127.6 & 1.76 & 0.99 \\
Skarn (water cooling) & 14.24 & 212.12 & 4.09 & 0.97 \\
\hline
\end{tabular}

prerequisites for using the Brazilian disc experimental tensile strength formula. The failure of the specimen at each temperature is the same type of split failure, that is, split failure occurs along the diameter direction. This shows that the temperature $\left(25 \sim 800^{\circ} \mathrm{C}\right)$ change will not affect the failure mode of the Skarn specimen in the Brazilian disc experiment, but will only deteriorate the tensile strength value of the Skarn specimen. 


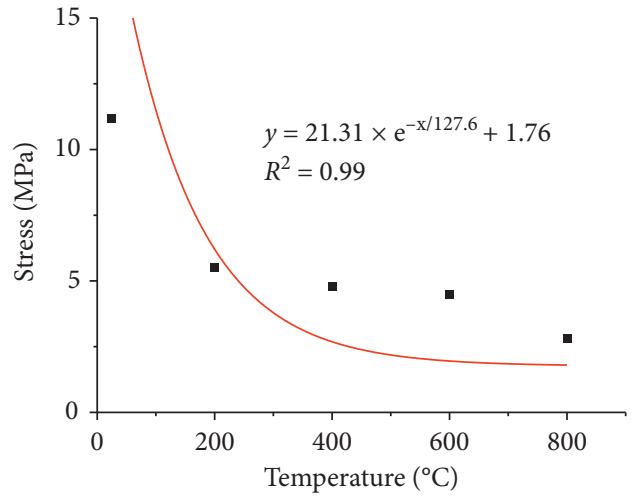

(a)



(b)

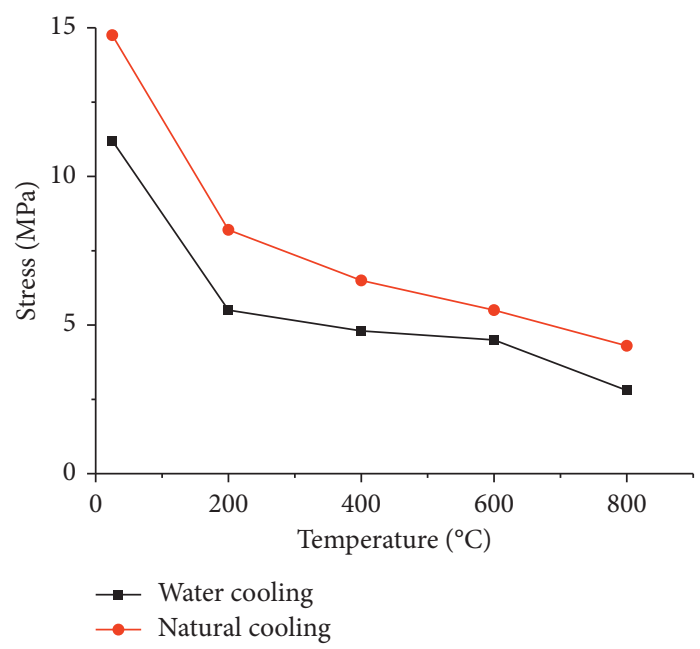

(c)

FIGURE 11: Relationship between tensile strength and temperature (natural cooling and water cooling). (a) Natural cooling; (b) water cooling; (c) effect of cooling mode on tensile strength of Skarn.

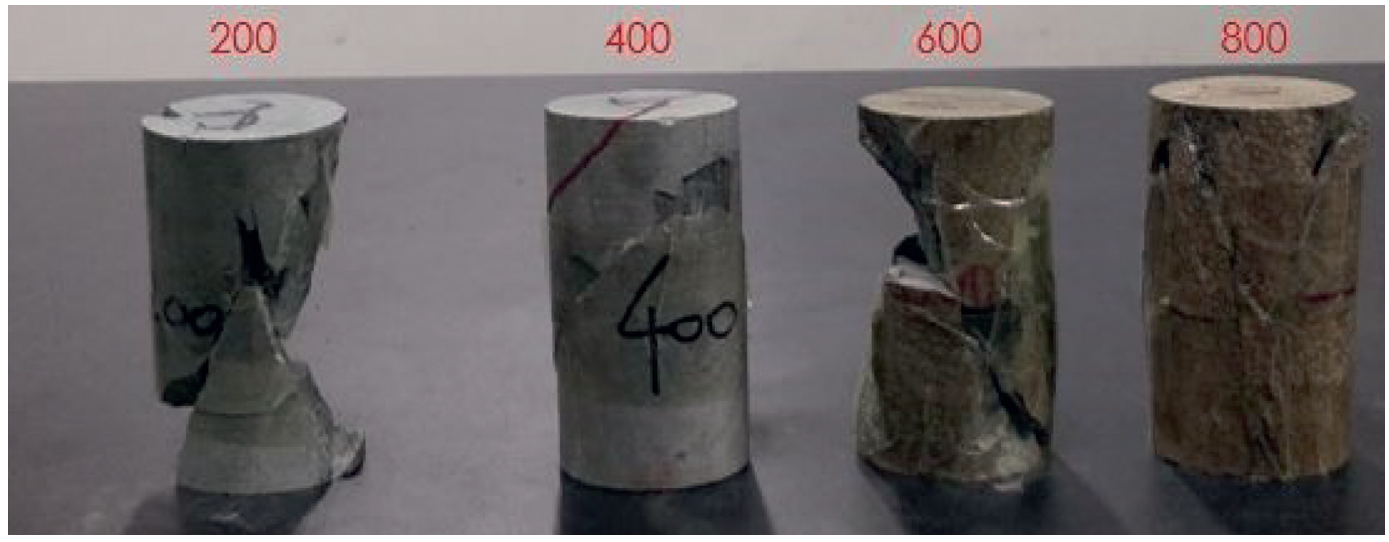

(a)

Figure 12: Continued. 


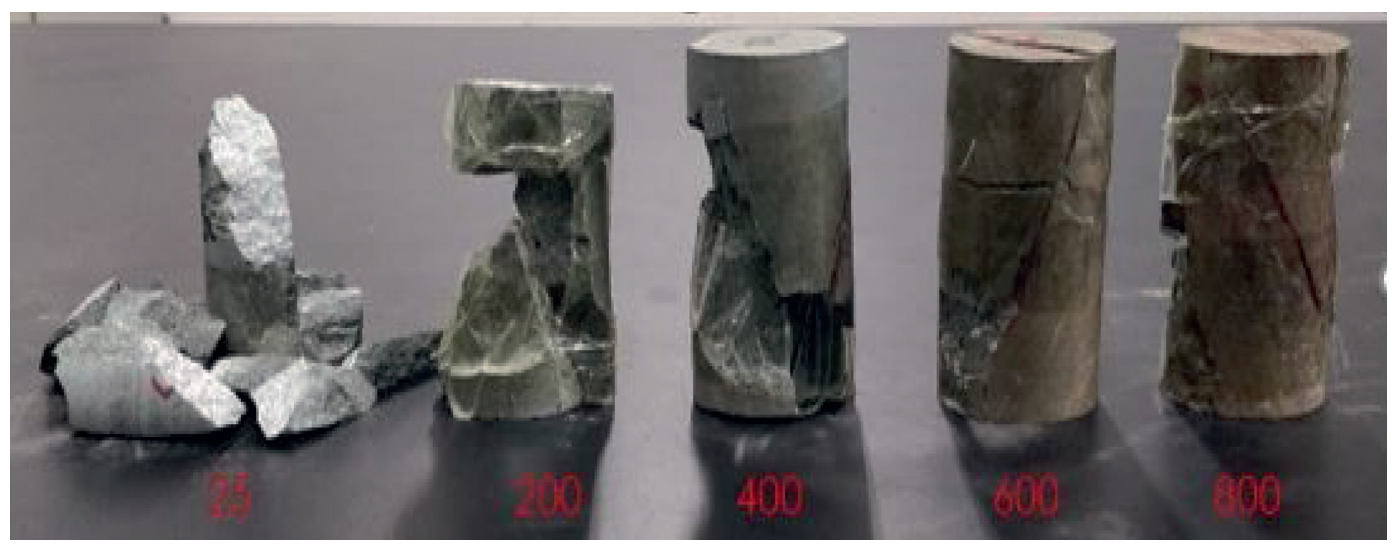

(b)

FIgURE 12: Failure mode of Skarn in uniaxial compression test. (a) Natural cooling; (b) water cooling.

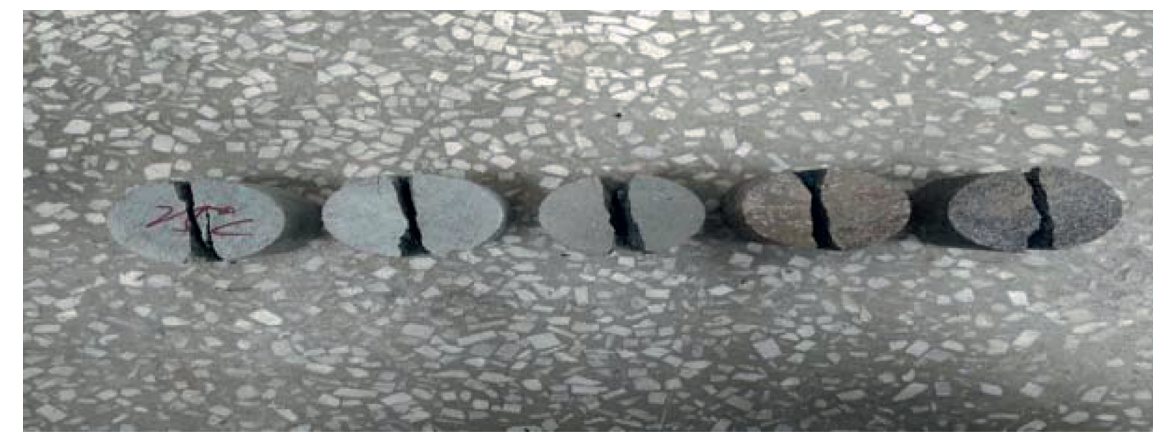

FIgURE 13: Failure mode of Brazilian disc splitting test for Skarn.

\section{Conclusion}

In this paper, the static mechanical properties of Skarn specimens after high temperature are studied through the static experimental system, which provides reference and basis for the study of dynamic mechanical properties of Skarn after high temperature, and the following conclusions are obtained:

(1) The uniaxial compressive strength of Skarn decreases linearly with increasing temperature. $400^{\circ} \mathrm{C}$ is the threshold temperature at which its compressive strength deteriorates. Both the elastic modulus and tensile strength decrease exponentially with the increase of temperature, and the peak strain increases exponentially with the increase of temperature. $400^{\circ} \mathrm{C}$ is the threshold temperature at which the peak strain of the Skarn rock changes. The above situation shows that high temperature $\left(25 \sim 800^{\circ} \mathrm{C}\right)$ will significantly degrade the strength and resistance to deformation of Skarn rock. Meanwhile, the increase in temperature will make the Skarn become "softer" and the ductility will be greatly improved.

(2) To compare the effects of air cooling and water cooling on the Skarn rock that has experienced high temperature $\left(25 \sim 800^{\circ} \mathrm{C}\right)$, the relationship between the four indexes (compressive strength, tensile strength, elastic modulus, and peak strain) of Skarn rock and the temperature changes is the research object. Studies have shown that the strength damage caused by water cooling on high-temperature Skarn is more severe than that caused by natural cooling, but the two cooling methods have no effect on the tendency of the mechanical properties of Skarn to decrease with increasing temperature. This shows that the deterioration of the mechanical properties of Skarn caused by the temperature effect is not related to the cooling method.

(3) It is found that under uniaxial compression load, the Skarn specimens are mainly in the form of shear failure. The specific shear failure surface is in the shape of "I," "V," and "X." Meanwhile, in the Brazilian disc splitting experiment, the Skarn specimens all cracked and failed along the diameter direction from the center, and all met the prerequisites for using the Brazilian disc experimental tensile strength formula. It shows that the temperature change will not affect the failure mode of the rock specimen in the Brazilian disc experiment, but will only reduce the tensile strength of the Skarn specimen.

\section{Data Availability}

The data used to support the findings of this study are included within the article. 


\section{Conflicts of Interest}

The authors declare that they have no conflicts of interest regarding the publication of this paper.

\section{Authors' Contributions}

Lei Liu designed experiments; Xiang Meng and Hao Qin carried out experiments; Zhaozhao Chang analyzed experimental results. Zhaozhao Chang and Lei Liu wrote the manuscript.

\section{Acknowledgments}

This research was supported by the National Natural Science Foundation of China (Grant nos. 11862010 and 51964023).

\section{References}

[1] S. Hibino, H. Komada, and H. Ito, "Feasibility assessment of the underground siting nuclear power plant," in Proceedings of the ANP'92 International Conference on Design and Safety of Advanced Nuclear Power Plants, Tokyo, Japan, October 1992.

[2] H. H. Melnikov, Y. Cao, D. Yuan et al., "Benefits and problems of underground goaf development," Foreign Metal Mines, no. 2, pp. 24-28, 1999.

[3] Q. Qian, "Development and utilization of underground space and urban sustainable development," Chinese Civil Air Defense, no. 5, pp. 29-30, 2005.

[4] Z. Q. Yin, Z. X. Hu, Z. D. Wei et al., "Assessment of blasting induced ground vibration in an OpenPit mine under different rock properties," Advances in Civil Engineering, vol. 2018, Article ID 4603687, 10 pages, 2018.

[5] J. Xu and S. Liu, High Temperature Dynamics of Rocks, Northwestern Polytechnical University Press, Xi'an, China, 2016.

[6] M. He, J. Miao, D. Li et al., "Experimental study on rockburst processes of granite specimen at great depth," Yanshilixue Yu Gongcheng Xuebao/Chinese Journal of Rock Mechanics and Engineering, vol. 26, no. 5, pp. 865-876, 2007.

[7] M. Wu, Test and Study on Dynamic Mechanical Properties of Rocks under High Temperatur, Anhui University of Science and Technology, Huainan, China, 2018.

[8] F. Frantz, "New experimental technique switch the split hopkin-son pressure bar," Journal of Physics E: Seientific lnstruments, vol. 15, pp. 280-282, 1982.

[9] L. James, "Threshold microfracture during elastic-plastic indentation of ceramics," Journal of Materials Science, vol. 16, pp. 1567-1578, 1981.

[10] L. Djapic Oosterkamp, A. Ivankovic, and G. Venizelos, "High strain rate properties of selected aluminium alloys," Materials Science and Engineering A, vol. 278, no. 1, pp. 225-235, 2000.

[11] I. Van der Molen, "The shift of the $\alpha-\beta$ transition temperature of quartz associated with the thermal expansion of granite at high pressure," Tectonophysics, vol. 73, no. 4, pp. 323-342, 1981.

[12] Y. Mahmutoglu, "Mechanical behaviour of cyclically heated fine grained rock," Rock Mechanics and Rock Engineering, vol. 31, no. 3, pp. 169-179, 1998.

[13] A. M. Ferrero and P. Marini, "Experimental studies on the mechanical behaviour of two thermal cracked marbles," Rock
Mechanics and Rock Engineering, vol. 34, no. 1, pp. 57-66, 2001.

[14] X. Xu, F. Gao, Z. Zhang et al., "Experimental study on the effect of loading rate on mechanical properties of granite under real-time high temperature," Rock and Soil Mechanics, vol. 38, no. 8, pp. 2184-2192, 2015.

[15] S. Liu and J. Xu, "Effect of High Temperature on dynamic compressive mechanical properties of granite," Journal of Vibration and Shock, vol. 33, no. 4, pp. 195-198, 2014.

[16] S. Liu, J. Xu, Z. Liu et al., "Experimental study on impact mechanics characteristics of marble after high temperature," Chinese Journal of Rock Mechanics and Engineering, vol. 32, no. 2, pp. 273-280, 2013.

[17] J. Xu, Z. Liu, L. Zhi et al., "Temperature effect on strength and damage property of rock Mass," Journal of Mining and Safety Engineering, vol. 30, no. 4, pp. 583-588, 2013.

[18] Z. Dong, Y. Zong, and X. Zhang, "Experimental study on mechanical characteristics of granite after being cooled by circulating heating water," Mining Research and Development, vol. 40, no. 5, pp. 113-118, 2020.

[19] H. Lin, W. Xiong, Z. Xiong, and F. Gong, "Three-dimensional effects in a flattened Brazilian disk test," International Journal of Rock Mechanics and Mining Sciences, vol. 74, pp. 10-14, 2015.

[20] H. Lin, W. Xiong, and Q. Yan, "Modified formula for the tensile strength as obtained by the flattened Brazilian disk test," Rock Mechanics and Rock Engineering, vol. 49, no. 4, pp. 1579-1586, 2016.

[21] S. K. Kourkoulis, C. F. Markides, and P. E. Chatzistergos, "The standardized Brazilian disc test as a contact problem," International Journal of Rock Mechanics and Mining Sciences, vol. 57, pp. 132-141, 2013. 